\title{
Malignant peripheral nerve sheath tumor with glandular elements arising in bone: a potential diagnostic pitfall
}

\author{
Shadi A. Qasem ${ }^{1}$, Joseph A. Buckwalter ${ }^{2}$, Barry R. DeYoung ${ }^{1}$ \\ 1. Department of Pathology, Wake Forest University School of Medicine, Winston Salem, NC, United States. 2. Department \\ of Orthopedics, University of I owa Hospitals and Clinics, Iowa City, Iowa, United States.
}

Correspondence: Shadi A. Qasem, M.D. Address: Wake Forest Baptist Health, Department of Pathology, Medical Center Boulevard,Winston-Salem, NC 27157, United States. Email: sqasem@wakehealth.edu

Received: March 4, 2014

Accepted: May 5, 2014

Online Published: May 21, 2014

DOI : $10.5430 /$ crcp.v1n2p112

URL: http://dx.doi.org/10.5430/crcp.v1n2p112

\section{Abstract}

We report a unique case of a malignant peripheral nerve sheath tumor with glandular differentiation arising in the tibial epiphysis of a 30 year old woman with no other significant medical history. Extensive histochemical and immunohistochemical analysis showed the epithelium lining the glands to exhibit gastrointestinal and neuroendocrine differentiation. The patient's clinical course had been one of multiple recurrences and distant metastases, almost exclusively of the spindle cell component of this biphasic neoplasm, culminating in the patient's demise. The differential diagnosis is discussed along with ancillary studies helpful in elucidating the appropriate diagnosis when confronted with a biphasic neoplasm exhibiting unequivocal glandular differentiation.

\section{Key words}

Malignant peripheral nerve sheath tumor, Bone, Epithelial, Glands, Neuroendocrine

\section{I ntroduction}

Primary intraosseous malignant peripheral nerve sheath tumors (MPNST) are rare, and the majority of these arise in the jaw $^{[1,2]}$. While many MPNST tumors are recognizable on morphological grounds, they can also be highly variable in histologic image, and sometimes indistinguishable from other mesenchymal neoplasms. The presence of heterologous elements in tumors exhibiting nerve sheath differentiation has been well-documented, often in the form of benign or malignant islands of cartilage or bone and less commonly skeletal muscle ${ }^{[3]}$. The most notable example of the latter being the so-called "triton tumor" which combines peripheral nerve sheath tumor with rhabdomyosarcomatous differentiation. In the following report, we discuss the case of a malignant triton tumor arising in the tibia of a young individual.

Epithelial differentiation in nerve sheath tumors, although less common, has long been reported ${ }^{[4,5]}$, but is uniformly confined to soft tissue. We report a case of MPNST with glandular elements presenting as a primary lesion in the bone. As one can imagine, MPNST with glands may be mistaken for metastatic adenocarcinoma, a diagnostic pitfall that one can learn from this extremely challenging case, especially on frozen section. Among sarcomas, synovial sarcoma is also famed for showing epithelial differentiation. The distinction of these two tumors from each other can be particularly difficult and 
often requires attention to subtle histologic details and the use of a battery of immunohistochemical stains. The histogenesis of glandular elements in a mesenchymal tumor is a controversial issue and has been discussed in other publications ${ }^{[3-5]}$. The most plausible theory seems to be that of divergent differentiation of a pluripotent mesenchymal cell.

\section{Case report}

The patient was a 30 year old female who presented with pain in the region of the left knee. The patient was previously healthy and had no history of neurofibromatosis. Physical examination was unremarkable. Radiologic evaluation of the left knee showed an epiphyseal-based lytic lesion involving the left medial tibial condyle which was felt to represent a giant cell tumor of bone (see Figure 1). There was no soft tissue involvement. An incisional biopsy was performed and a diagnosis of metastatic adenocarcinoma from an occult primary was rendered. Clinical work-up, including computerized tomography of the chest, abdomen, and pelvis, was negative. Despite radiation therapy, the tibial lesion progressed, and eight months later an en-bloc resection was performed with a resulting diagnosis of low grade spindle cell malignancy. The glandular component, which had been conspicuous in the first biopsy, was essentially absent at this point.

Figure 1. Radiograph of the left knee showing an epiphyseal/metaphyseal lytic lesion involving the left medial tibial condyle

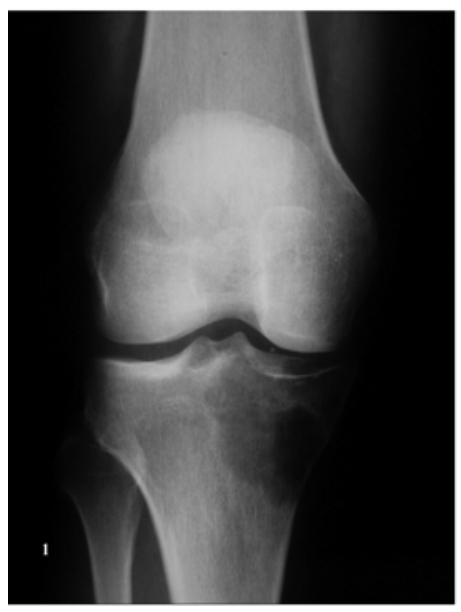

Subsequently, the patient had a second recurrence which warranted an above the knee amputation. The clinical course afterwards included osseous metastasis to the 8th rib treated by resection followed by sarcoma based chemotherapy. The patient eventually developed spinal cord metastasis, not amenable to resection. She died with disease five years after the initial diagnosis.

Microscopic examination of the original biopsy showed complete destruction of the normal bony architecture by infiltrating atypical mucinous glands surrounded by a low grade spindle cell proliferation composed of mildly pleomorphic cells with wavy "buckled" nuclei and pink eosinophilic cytoplasm. This was initially interpreted as a brisk desmoplastic response. A second cell population was identified composed of solid nests of cells with more ovoid nuclei, minimal cytoplasm and a stippled chromatin pattern suggestive of neuroendocrine differentiation. The recurrences, on the other hand, were composed of almost exclusively the spindle cell component. Hemorrhage and necrosis were not prominent features. A rare gland was identified in the first recurrence, while the second recurrence lacked epithelial differentiation despite extensive sectioning. A mucicarmine stain highlighted both luminal and cytoplasmic mucin in the original biopsy (see Figure 2).

Immunohistochemical analysis of the original tumor showed the glandular component to be strongly immunoreactive with antibodies directed against cytokeratin (AE1/AE3), low molecular weight cytokeratin and cytokeratin 20. The second population of smaller "neuroendocrine-like" cells was positive for cytokeratin (AE1/3) and chromogranin. Both epithelial components showed negative staining for cytokeratin 7, S100 protein, CD57, HMB45, EMA and CD99. This phenotype was in contrast to that observed in the spindle cell component in the same tumor, as well as the recurrences. The spindle 
cells were immunoreactive with antibodies directed against vimentin, CD57 and S100 protein. The staining with the latter two markers was focal and distributed throughout the lesion while vimentin staining was diffuse and rather intense. The spindle cells were uniformly negative for all the cytokeratins and EMA. They were also negative for HMB45, smooth muscle actin, muscle specific actin, and CD99 (see Figure 3).

Figure 2. Morphologic features of the tumor. A. Low power view showing a glandular tumor infiltrating mesenchymal tissue $(4 \times)$. B. Mucinous glands showing goblet-cell differentiation $(40 \times)$. C. Solid nests of neuroendocrine- appearing cells $(20 \times)$. D. mucicarmine stain highlighting both intra- and extra-cytoplasmic mucin $(40 \times)$. E. Focal residual bone trabeculae $(10 \times)$. F. Spindle cell component showing buckled wavy nuclei (20×). G and H. low and high power views of metastatic tumor showing a pure spindle cell neoplasm with a vague storiform pattern (4× and 20×, respectively). All except $\mathrm{D}$ are hematoxylin and eosin; $\mathrm{D}$, mucicarmine stain.

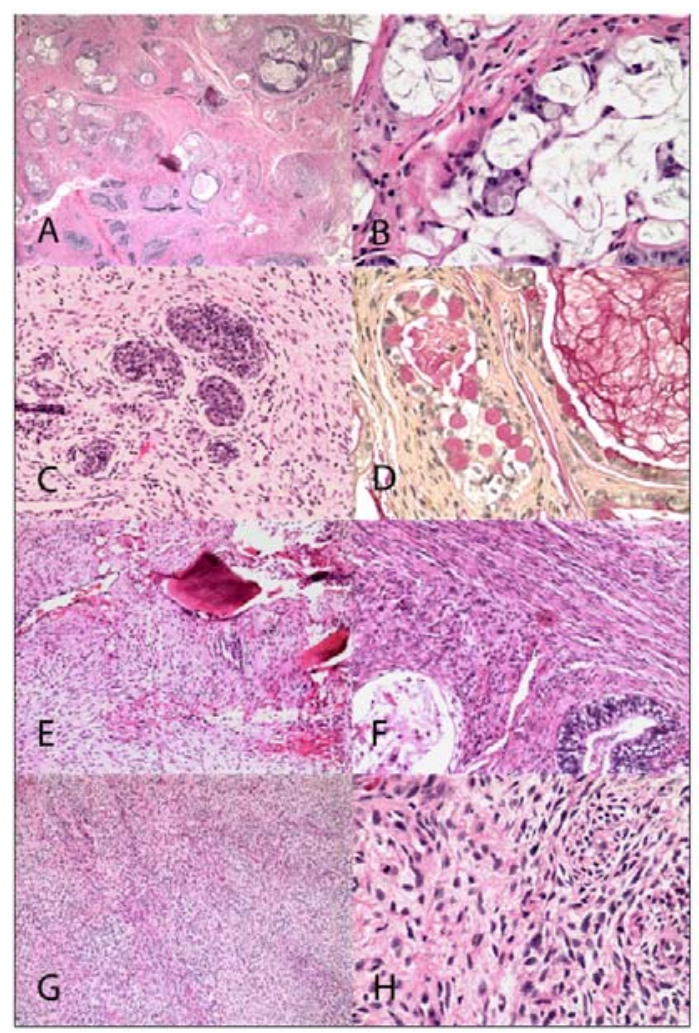

Figure 3. Immunohistochemical stains. A. cytokeratin 20 stain highlighting glandular component $(10 \times)$. B. Chromogranin stain is positive in the neuroendocrine component (10×). $\mathrm{C}$ and D. low and high power views of the S100 stain showing only focal positivity $(4 \times$ and $20 \times$ respectively).

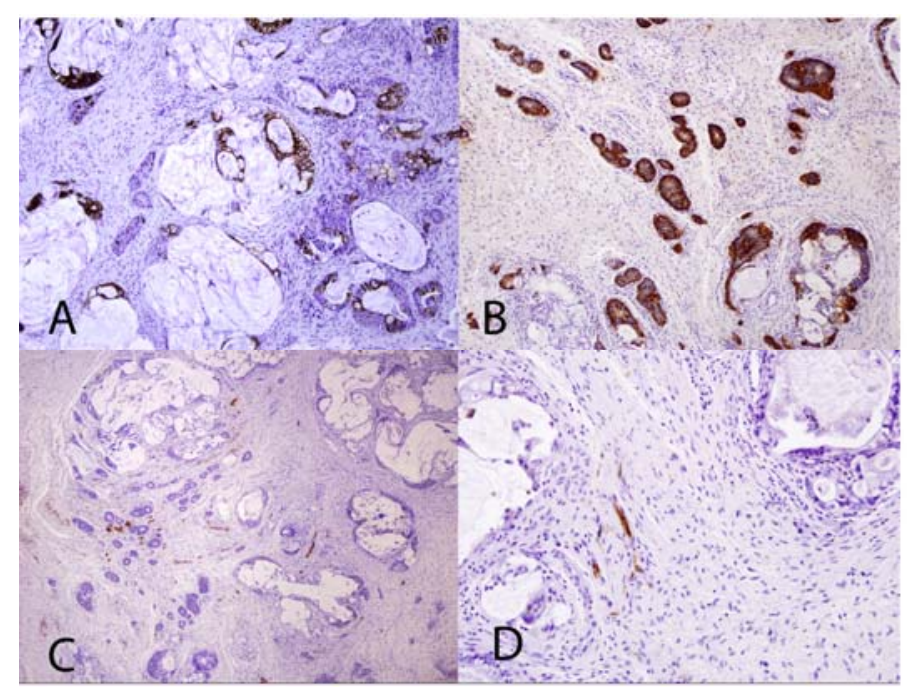

\section{Discussion}

Peripheral nerve sheath tumors exhibiting glandular differentiation have long been reported in soft tissue. The first report dates back to 1892 by Garre who described a case of peripheral nerve tumor with epithelial glands arising in a patient with neurofibromatosis. This report was accompanied by camera lucida drawings showing a spindly tumor with a woven pattern containing numerous glands (as reported by Woodruff et al.) ${ }^{[5]}$. Scattered individual cases have been reported 
since with a large percentage of the work being performed by Woodruff and associates ${ }^{[5-8]}$. He first reported a series of five such neoplasms in 1976, with subsequent studies showing the presence of neuroendocrine differentiation within the glandular component, and the subtyping of the glandular epithelium as intestinal ${ }^{[9,10]}$. In fact, more than one author has shown that the glandular epithelium was positive for regulatory peptides and amines such as somatostatin, serotonin, pancreatic polypeptide and gastrin ${ }^{[10,11]}$. The intestinal differentiation was supported by ultrastructural findings of a polarized epithelium with tight junctions, glycocalyx, R-bodies and luminal microvilli with core rootlets ${ }^{[4,11]}$.

MPNST with glands is very rare in the appendicular skeleton. Cases of glandular MPNST have been reported in the spine, but they all seem to have an extra-osseous component ${ }^{[12]}$, hence they are believed to arise in the spinal roots with secondary bone involvement. The differential diagnosis of MPNST with glandular differentiation includes metastatic adenocarcinoma with an exuberant desmoplastic response, metastatic malignant mixed Mullerian tumor and other sarcomas with glandular differentiation such as synovial sarcoma. Occurring in bone, one would also have to add Adamantinoma to the list. Metastatic carcinomas can usually be excluded based on clinical grounds and an extensive clinical work up. In Adamantinoma, the epithelial component usually resembles ameloblastic epithelium, does not show intestinal differentiation, and the stroma lacks the S100 protein reactivity.

The distinction between synovial sarcoma and MPNST with glandular elements can be difficult, and has been discussed in more than one publication ${ }^{[11,13]}$. Both are spindle cell sarcomas with epithelial differentiation, and neither one has a distinct immunohistochemical profile. For example, S100 protein and CD57 which are commonly associated with peripheral nerve sheath tumors can also be positive in a subset of synovial sarcomas ${ }^{[14]}$. Morphologic characteristics that have been described as being useful include a sharp distinction between the stromal and the glandular components, goblet cell formation and intra-cytoplasmic mucin in MPNST but not in synovial sarcoma ${ }^{[5,8,10,11]}$. Immunohistochemically, the spindle cells in MPNST do not express epithelial markers, while the spindle cells in synovial sarcoma frequently show evidence of epithelial differentiation, including cytokeratin and EMA ${ }^{[14]}$. With the advent of cytokeratins 7 and 20, it has been shown that synovial sarcomas express cytokeratin 7 and not cytokeratin 20, while the opposite is true for the glandular elements in MPNST ${ }^{[14]}$. The glands in MPNST are also positive for CEA, a finding uncommonly seen in synovial sarcoma ${ }^{[11]}$.

Chromogranin expression can be utilized as a helpful adjunct, as MPNST with glandular elements frequently contain both single cells and small clusters that recapitulate the neuroendocrine cells of the intestine ${ }^{[11]}$. The vast majority of synovial sarcomas show positive staining with CD99, while MPNST is rarely positive for this marker ${ }^{[10]}$. A newly described antibody (TLE1) is positive in the majority of synovial sarcoma cases, but only rarely in MPNST ${ }^{[15]}$. Lastly, with the increasing availability of molecular testing on paraffin embedded tissue, it is possible to test for the $t(X ; 18)$ translocation which has been shown to be positive in up to $90 \%$ of cases of synovial sarcoma ${ }^{[13]}$.

In the vast majority of the previously reported cases of MPNST with glandular differentiation, the glandular epithelium has been described as benign, with only a few reports of malignant glandular epithelium ${ }^{[7,8]}$. Christensen and Woodruff noticed that the degree of atypia of the glandular epithelium did not correlate with the degree of atypia in the spindle cells ${ }^{[11]}$. It is generally thought that MPNST with glandular differentiation behaves in a similar fashion to those without glands. In fact, when these tumors metastasize, the metastases are mostly composed of the spindle cell component, as seen in our case. It is the grade of the spindle cell component that is more important in this regard ${ }^{[3,5,6,9]}$. Woodruff reported a mean survival of two years and $79 \%$ of patients eventually dying with disease ${ }^{[8]}$.

In summary, MPNST should be considered in the differential diagnosis of a biphasic neoplasm composed of spindle cells and glandular elements, especially in bone and soft tissue. The differential diagnosis includes synovial sarcoma, as well as metastatic adenocarcinoma with the latter being a particular diagnostic pitfall if appropriate attention is not given to the spindle cell component. A battery of immunohistochemical stains in conjunction with thorough histologic examination can be used to help confirm the diagnosis. 


\section{References}

[1] Bullock MJ, Bedard YC, Bell RS, Kandel R. Intraosseous malignant peripheral nerve sheath tumor. Report of a case and review of the literature. Arch Pathol Lab Med. 1995; 119(4): 367-370. PMid: 7726730.

[2] Khan RJ, Asgher J, Sohail MT, Chughtai AS. Primary intraosseous malignant peripheral nerve sheath tumor: A case report and review of the literature. Pathology. 1998; 30(3): 237-241. PMid: 9770186. http://dx.doi.org/10.1080/00313029800169376

[3] Weiss SW, Goldblum JR. Malignant tumors of the peripheral nerves. In: Weiss SW, Goldblum JR, eds. Enzinger and Weiss’s Soft Tissue Tumors. 5th ed. Mosby. 2008; 903-944.

[4] Uri AK, Witzleben CL, Raney RB. Electron microscopy of glandular schwannoma. Cancer. 1984; 53(3): $493-497$. http://dx.doi.org/10.1002/1097-0142(19840201)53:3<493::AID-CNCR2820530320>3.0.CO;2-M

[5] Woodruff JM. Peripheral nerve sheath tumors showing glandular differentiation (glandular schwannomas). Cancer. 1976; 37(5): 2399-2413. http://dx.doi.org/10.1002/1097-0142(197605)37:5<2399::AID-CNCR2820370532>3.0.CO;2-2

[6] Michel SL. Epithelial elements in a malignant neurogenic tumor of the tibial nerve. Am J Surg. 1967; 113(3): 404-408. http://dx.doi.org/10.1016/0002-9610(67)90288-7

[7] Nagasaka T, Lai R, Sone M, Nakashima T, Nakashima N. Glandular malignant peripheral nerve sheath tumor: an unusual case showing histologically malignant glands. Arch Pathol Lab Med. 2000; 124(9): 1364-1368. PMid: 10975940.

[8] Woodruff JM, Christensen WN. Glandular peripheral nerve sheath tumors. Cancer. 1993; 72(12): 3618-3628. http://dx.doi.org/10.1002/1097-0142(19931215)72:12<3618::AID-CNCR2820721212>3.0.CO;2-\#

[9] Huang L, Espinoza C, Welsh R. Malignant peripheral nerve sheath tumors with divergent differentiation. Arch Pathol Lab Med. 2003; 127(3): e147-150. PMid: 12653604.

[10] Warner TF, Louie R, Hafez GR, Chandler E. Malignant nerve sheath tumor containing endocrine cells. Am J Surg Pathol. 1983; 7(6): 583-590. PMid: 6137966. http://dx.doi.org/10.1097/00000478-198309000-00009

[11] Christensen WN, Strong EW, Bains MS, Woodruff JM. Neuroendocrine differentiation in the glandular peripheral nerve sheath tumor. Pathologic distinction from the biphasic synovial sarcoma with glands. Am J surg Pathol. 1988; 12(6): 417-426. PMid: 2837100. http://dx.doi.org/10.1097/00000478-198806000-00001

[12] Miyakoshi N, Nishikawa Y, Shimada Y, Okada K, Yoshida M, Enomoto K, et al. Intraosseous malignant peripheral nerve sheath tumor with focal epithelioid differentiation of the thoracic spine. Neurol India. 2007; 55(1): 64-6. PMid: 17272904. http://dx.doi.org/10.4103/0028-3886.30431

[13] Folpe AL, Schmidt RA, Chapman D, Gown AM. Poorly differentiated synovial sarcoma: immunohistochemical distinction from primitive neuroectodermal tumors and high-grade malignant peripheral nerve sheath tumors. Am J Surg Pathol. 1998; 22(6): 673-682. PMid: 9630174. http://dx.doi.org/10.1097/00000478-199806000-00004

[14] Lisa AC, Mark RW. Immunohistology of soft tissue and osseous neoplasms. In Dabbs DJ, ed. Diagnostic Immunohistochemistry. 2nd edition. Elsevier. 2006; 91-93.

[15] Terry J, Saito T, Subramanian S, Ruttan C, Antonescu CR, Goldblum JR. TLE1 as a diagnostic immunohistochemical marker for synovial sarcoma emerging from gene expression profiling studies. Am J Surg Pathol. 2007; 31(2): 240-6. PMid: 17255769. http://dx.doi.org/10.1097/01.pas.0000213330.71745.39 